\title{
Antibiotics Sensitivity and Heavy Metals Resistance in PHB-Producing Bacilli Isolated from Eastern Province, Saudi Arabia
}

\author{
Mahmoud Berekaa $^{{ }^{*}}$, Khaled Salama ${ }^{1}$ and Khaled Alkharsah ${ }^{2}$ \\ ${ }^{1}$ Environmental Health Department, College of Applied Medical Sciences \\ ${ }^{2}$ Department of Epidemic Disease Research, Institute for Research and Medical Consultations, University of Dammam, \\ Dammam, Saudi Arabia \\ *For correspondence: mberekaa@uod.edu.sa
}

\begin{abstract}
There has been considerable interest in development and industrial production of polyhydroxybutyrate (PHB) biopolymers from bacteria due to its potential applications in agriculture, health and medicine. However, it is recommended to evaluate PHB-producing bacteria regarding sensitivity to antibiotics, resistance to heavy metals and possible toxicity before large scale production of the biopolymer. In this study, 120 bacterial strains isolated from different soil and sewage water samples in Eastern Province, Saudi Arabia, and screened for PHB production. Sixteen strains showed positive results with Sudan Black B and Nile Red A stains. 16S DNA gene analysis revealed high homologies to members of Bacillus cereus group, B. megaterium, B. flexus, B. endophyticus, and B. aryabhattai. For antibiotic profiling; B. cereus DS3-16 and B. thuringiensis DST1-33 showed highest resistance, especially to ampicillin, erythromycin and amoxicillin, while the least were $B$. megaterium DG8, DP7 and B. pseudomycoides DWST2-1. Bacillus sp. DSG5 and DPS6 followed by DSWT2-1, DS3-17 and DS3-12 showed highest resistance to $\mathrm{Cr}^{+6}(10 \mathrm{mg} / \mathrm{mL})$, as well as $\mathrm{Hg}(62.5 \mu \mathrm{g} / \mathrm{mL})$ and $\mathrm{Ag}(5 \mathrm{mg} / \mathrm{mL})$, respectively while most strains were highly susceptible to other metals. Four isolates including B. cereus strain DS3-16 showed $\beta$-hemolysis activity, while Bacillus axarquiensis DSG5 showed $\alpha$-hemolytic activity, indicating their possible toxicity. (C) 2016 Friends Science Publishers
\end{abstract}

Keywords: PHB biopolymer; Antibiotic sensitivity; Heavy metal resistance; Profiling; Bacillus sp.

\section{Introduction}

There is an increasing demand for production of many biobased products including biopolymers to be used in agriculture, health, and medicine. Decades have been devoted on extensive research to develop biodegradable polymers as a promising substitute for petrochemical-based polymers due to their eco-friendly nature (Ojumu et al., 2004). Among most commonly known bio-products is the bioplastic. When carbon source nutrients are available in excess relative to other nutrients in the growth environment, certain strains of bacteria produce and accumulate different types of polyester recognized as bioplastics, which have unique characteristics like biodegradability and biocompatibility (Madison and Huisman, 1999; Kim and Lenz, 2001; Steinbuchel, 2001; Ojumu et al., 2004; Reddy et al., 2009; Nayak et al., 2013). Among widely known bioplastics, polyhydroxybutyrate (PHB) is the most prevailing polyester owing to its great resemblance to synthetic petroleum-derived synthetic plastic polymers (Mokhtari-Hosseini et al., 2009; Berekaa and Al-Thawadi, 2012). Bioplastics have diversity of applications in medicine, tissue engineering, veterinary uses, agriculture, as well as food packaging (van der Walle et al., 2001; Zinn et al., 2001; Borah et al., 2002; Luengo et al., 2003).

It is well known that, our environment is contaminated with antibiotics and heavy metals originated from natural sources as well as direct or indirect human activities such as rapid industrialization, urbanization, and from human activities or anthropogenic activities (Krishnani and Ayyappan, 2006). Heavy metals used in industry and in domestic products, along with antibiotics used in agriculture, hospitals, animal husbandry, industry and prophylaxis, generating selective pressure that may leads to mutations for better survival under unfavorable conditions (Baquero et al., 1998).

Interestingly, production of biopolymer during pilot studies or in industrial scale is greatly contaminated by environmental heavy metal especially in fermenters. De Lima et al. (1999) mentioned that PHA biopolymers production in industrial scale is strongly affected by heavy contamination from environment in the fermenter. Therefore, it is highly crucial to exploit the potent biopolymer producing strains regarding antibiotics and

To cite this paper: Berekaa, M., K. Salama and K. Alkharsah, 2016. Antibiotics sensitivity and heavy metals resistance in PHB-producing bacilli isolated from eastern province, Saudi Arabia. Int. J. Agric. Biol., 18: 1232-1236 
heavy metal resistance for controlling contamination before industrial production of the polymer (De Lima et al., 1999; Rehman et al., 2007; Razzaq et al., 2010; Naheed et al., 2011).

The purpose of this research is the study of factors controlling contaminants before industrial production of PHB biopolymer. Group of bacteria were isolated from soil or sewage samples in Eastern Province, Saudi Arabia, and screened for PHB production. Molecular characterization of the potent PHB-producing candidates was thoroughly investigated. Prominence was given to evaluation of biopolymer producing bacteria regarding sensitivity to antibiotics and resistance to heavy metals. Possible toxicity of PHB-producing bacteria to human health was also detected.

\section{Materials and Methods}

\section{Sampling, Isolation and Screening for PHB Production}

Collection of soil and sewage samples using sterile containers and bottles, from different areas (Dammam, AlKhobar, Qateif and Al-Hassa) in Eastern Province, Saudi Arabia. Isolation of bacteria was carried out as following; soil or sewage sample was diluted in sterile distilled water and $0.1 \mathrm{~mL}$ was plated on nutrient agar (NA plates) with the following composition (g/L); Peptone 5; beef 3; $\mathrm{NaCl} 5$ and agar 15. Separate colonies were isolated and further purified. The purified strains were subjected to screening for PHB production after cultivation on three different mineral salts production media: M1 or modified E2 medium (Berekaa and Al-Thawadi, 2012), M2 medium (g/L): ammonium sulfate; 2, $\mathrm{KH}_{2} \mathrm{PO}_{4} ; 6.67,\left(\mathrm{NH}_{4}\right) \mathrm{HPO}_{4} ; 4$, $\mathrm{MgSO}_{4} .7 \mathrm{H}_{2} \mathrm{O} ; 0.8,5 \mathrm{~mL}$ traces element solution $(\mathrm{HCl}, 5$; $\mathrm{FeSO}_{4} .7 \mathrm{H}_{2} \mathrm{O}, 10 ; \mathrm{CaCl}_{2} 2 ; \mathrm{MnSO}_{4} .4 \mathrm{H}_{2} \mathrm{O}, 0.5 ; \mathrm{ZnSO}_{4} .7 \mathrm{H}_{2} \mathrm{O}$, 2.2; $\mathrm{CuSO}_{4} .5 \mathrm{H}_{2} \mathrm{O}, 1.9 ;\left(\mathrm{NH}_{4}\right) \mathrm{Mo}_{7} \mathrm{O}_{24} 0.1 ; \mathrm{Na}_{2} \mathrm{~B}_{4} \mathrm{O}_{7} .10 \mathrm{H}_{2} \mathrm{O}$, $0.02)$ and $\mathrm{M} 3$ medium $(\mathrm{g} / \mathrm{L})$ : glucose, 10 ; ammonium sulfate; $2, \mathrm{KH}_{2} \mathrm{PO}_{4} ; 0.5, \mathrm{MgSO}_{4} .7 \mathrm{H}_{2} \mathrm{O} ; 0.2, \mathrm{NaCl} ; 0.1$, peptone; 2.5 and yeast extract; 2.5 ) and incubation at $37^{\circ} \mathrm{C}$. After sterilization of media, filter-sterilized stain was added (Sudan Black B $0.3 \mathrm{~g}$ in 70\% Ethanol and Nile Red A stock solution $0.25 \mathrm{~g} / \mathrm{mL}$ DMSO, use $20 \mu \mathrm{L}$ to reach final concentration of $0.5 \mu \mathrm{g} / \mathrm{mL}$ ).

\section{Antibiotics and Heavy Metals Profiling}

Potent PHB-producing strains were screened for antibiotic sensitivity through sensitivity test using Mueller Hinton agar medium as well as Agar Sensitivity Test medium (BioWorld, USA) (Bauer et al., 1966). Eight different antibiotics used in this study namely; Ampicillin $(10 \mu \mathrm{g})$, Erythromycin $(5 \mu \mathrm{g})$, Tetracycline $(30 \mu \mathrm{g})$, Kanamycin $(30$ $\mu \mathrm{g})$, Streptomycin $(10 \mu \mathrm{g})$, Ciprofloxacin $(5 \mu \mathrm{g})$, Neomycin $(30 \mu \mathrm{g})$, and Amoxicillin $(30 \mu \mathrm{g})$. All antibiotics purchased from (BD BBLTM, USA), except Amoxicillin from (HARDY diagnostic, USA). For heavy metal resistance profiling different concentrations of the following metals were tested; $\mathrm{AgNO}_{3}, \mathrm{ZnSO}_{4}, \mathrm{CdCl}_{2}, \mathrm{PbNO}_{3}$ (stock solution: $0.4 \mathrm{~g} / \mathrm{mL}$ ); $\mathrm{K}_{2} \mathrm{Cr}_{2} \mathrm{O}_{7}$ (stock solution: $0.2 \mathrm{~g} / \mathrm{mL}$ ) and $\mathrm{HgCl}_{2}$ (stock solution: $0.1 \mathrm{~g} / \mathrm{mL}$ ).

\section{Cultivation on Blood Agar}

To test hemolytic activity, PHB-producing strains tested for hemolytic activity by cultivation on blood agar medium (Bioworld, USA).

\section{Molecular Identification by 16S RNA Gene Analysis}

Molecular identification of the bacterial strains was carried out by amplification of 16S RNA gene using set of primers listed in Table 1. After PCR amplification and subsequent sequencing, the DNA sequences of 16S RNA genes were analyzed by BLAST search on Genbank database of NCBI, NIH, USA.

\section{Results}

\section{Screening and Molecular Identification}

In a program for isolation of PHB-producing bacteria, a group of 120 bacterial strains were isolated from soil and sewage specimens from Eastern Province (Dammam, AlKhobar, Qateif and Al-Hassa), Saudi Arabia. The strains were further purified and subjected to screening for PHB production by cultivation on the three PHA production media and subsequently tested by staining with Sudan Black B stain and Nile Red A. Positive strains showed blue-black colonies with Sudan black stain and red fluorescence after staining with Nile Red A and exposure to UV (Fig. 1).

Among screened bacteria, 16 strains showed clear positive results with both dyes, and thus chosen for further investigation. Molecular identification by 16S RNA gene analysis indicated that most of the isolated strains are bacilli belong mainly to members of Bacillus cereus group, $B$. megaterium, $B$. flexus, $B$. endophyticus, and $B$. aryabhattai. The potent PHB-producing candidates were given specific names, 16S DNA nucleotide sequence deposited in DNA Genbank and accession numbers are provided in Table 2.

\section{Antibiotic Sensitivity and Heavy Metals Resistance Profiling}

Eight different antibiotics were used to profile antibiotic sensitivity among PHB-producing candidates. Results indicated that all bacterial candidates are sensitive to most of tested antibiotics. However, bacterial strains $B$. cereus strain DS3-16 and B. thuringiensis strain DST133 recorded the highest resistance, especially to ampicillin, erythromycin and amoxicillin, while the least sensitive were $B$. megaterium strain DG8, strain DP7 and B. pseudomycoides strain DWST2-1 (Fig. 2a). 
Table 1: List of primers used for amplification of 16S RNA gene from potent PHB producing strains

\begin{tabular}{lll}
\hline Label & Sequence & Reference \\
\hline SFC1 & 5'-AGR GTT TGA TCM TGG CTC AG-3' & Hoseinabadi et al., 2015 \\
SRC1 & 5'-TAC GGY TAC CTT GTT AYGG ACT T-3' & Hoseinabadi et al., 2015 \\
SRC2 & 5'-AAG GAG GTG ATC CAA CCG-3' & Logan et al., 2000 \\
SF1 & 5'-GAG TTT GAT CMT GGC TCA G-3' & El-Helow, 2001 \\
SR2 & 5'- TAC GGY TAC CTT GTT ACG ACT T-3' & El-Helow, 2001 \\
\hline
\end{tabular}

Table 2: DNA Sequence analysis of 16S RNA gene and hemolytic activity of PHB-producing candidates

\begin{tabular}{llllll}
\hline Bacterial strain & Accession number & Hemolytic activity & Bacterial strain & Accession number & Hemolytic activity \\
\hline B. thuringiensis DST1-33 & KU199803 & B & B. megaterium DP7 & KU199812 & Non \\
B. endophyticus DS43 & KU199806 & Non & B. flexus DS3-17 & KU199813 & Non \\
B. megaterium DPS6 & KU199807 & Non & B. cereus DS3-16 & KU199814 & $\beta$ \\
B. axarquiensis DSG5 & KU199808 & $\alpha$ & B. cereus DS3-12 & KU199815 & $\beta$ \\
B. sp. DS3-14 & KU199805 & Non & B. pseudomycoides DWST2-1 & KU199816 & $\beta$ \\
B. megaterium DG8 & KU199809 & Non & B. mycoides DWST2-2 & KU199817 & Non \\
B. aryabhattai DBS10 & KU199810 & Non & B. anthracis DWST2-3 & KU199818 & Non \\
B. megaterium DT7 & KU199811 & Non & B. megaterium DPS8 & KU199804 & Non \\
\hline
\end{tabular}

On the other hand, profiling of heavy metal resistance among the group of PHB-producing bacteria indicated that Bacillus sp. strains DSG5, DPS6 followed by DSWT2-1, DS3-17 and DS3-12 showed highest resistance to $\mathrm{Cr}^{+6}(5 \mathrm{mg} / \mathrm{mL})$ as well as $\mathrm{Hg}(62.5 \mu \mathrm{g} / \mathrm{mL})$ and $\mathrm{Ag}(10$ $\mathrm{mg} / \mathrm{mL}$ ), respectively while, other strains showed higher susceptibility to all metals including; $\mathrm{Cd}, \mathrm{Zn}$ and $\mathrm{Pb}(10$ $\mathrm{mg} / \mathrm{mL}$ ) (Fig. 2b).

\section{Cultivation on Blood Agar}

To test the possible toxicity of the PHB-producing candidates, hemolytic activity of the potent bacterial candidates was monitored by cultivation on Blood Agar medium. Results in Table 2 indicated that four isolates including; $B$. cereus strain DS3-16 and strain DS3-12, $B$. thuringiensis strain DST1-33 and B. pseudomycoides strain DWST2-1 showed $\beta$-hemolysis activity, while $B$. axarquiensis strain DSG5 showed $\alpha$-hemolytic activity, reflecting their possible toxicity. However, B. mycoides strain DWST2-2, B. aryabhattai strain DBS10, $B$. endophyticus DS43 and $B$. megaterium strain DP7 are common soil non-pathogenic bacteria, recorded no hemolytic activity.

\section{Discussion}

A group of 120 bacterial strains isolated from soil and sewage specimens from Eastern Province, Saudi Arabia and screened for PHB production carried out by the use of several dyes. Sixteen strains showed blue-black colonies with Sudan black stain (non-specific for any lipid particles) and colonies with red fluorescence after staining with Nile Red and exposure to UV (specific for PHB). Generally, the dynamic status of our ecosystem contaminates soils with large diversity of PHB-producing bacteria (De Lima et al., 1999). Chen reported the tremendous activity of bacteria in production of polyhydroxyalkanoates as a promising polymer for drug delivery and as biofuel (Chen, 2010). Chen et al. (2001) isolated 54 bacterial strains $97 \%$ were PHA producers as anticipated from Sudan black B and Nile Blue A staining. Molecular identification of the isolates indicated that all PHB-producing strains with highest homology to bacilli, especially members of $B$. cereus group namely; $B$. pseudomycoides, $B$. mycoides, $B$. cereus and $B$. anthracis, in addition to other bacilli namely; $B$. megaterium, B. flexus, B. endophyticus and B. aryabhattai. Interestingly, production of PHB by bacteria belong to this this group was recently reported (Valappil et al., 2007; Aarthi and Ramana, 2011; Narayanan and Ramana, 2012). Narayanan and Ramana (2012) managed to isolate $B$. mycoides DFC1 from garden soil and optimized PHB production by central composite design.

Unlike PHB biopolymer produced from gram negative bacteria, biopolymer produced from gram positive bacteria especially bacilli is known to be free from toxic compounds especially outer membrane lipopolysaccharide (LPS) endotoxins that could induce severe immunogenic reaction (Chen et al., 2005). Lee et al. (1999) made an attempt to remove endotoxins, while purifying the poly (3hydroxybutyrate) from Gram-negative bacteria. Moreover, PHB-producing bacilli are capable of rapid growth on a variety of cost-effective substrates, while gram-negative bacteria require expensive substrates which should be structurally related substrate to produce the PHAs polymer. Therefore, large numbers of bacilli are used in PHAs production and recommended for biomedical applications (Chen et al., 1991; Wu et al., 2001; Yilmaz et al., 2005; Valappil et al., 2007; Singh et al., 2009; Lopez-Cortes et al., 2010; Mizuno et al., 2010).

Our environment steadily gets overloaded with heavy metals and antibiotics contaminants from natural sources as well as human activities e.g., industrialization and urbanization activities (Krishnani and Ayyappan, 


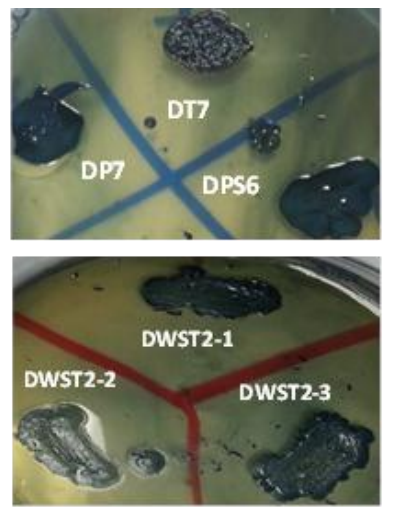

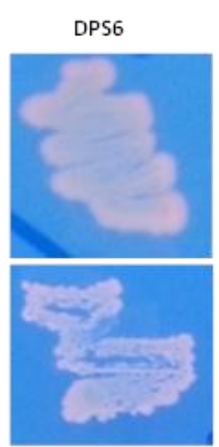

DS3-12

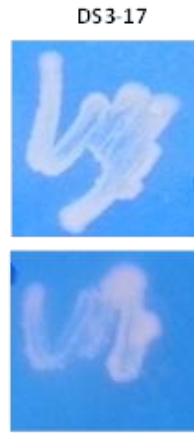

DPS8
Fig. 1: Screening for PHB producing bacteria by staining with Nile Red A (right) and Sudan Black B (left)

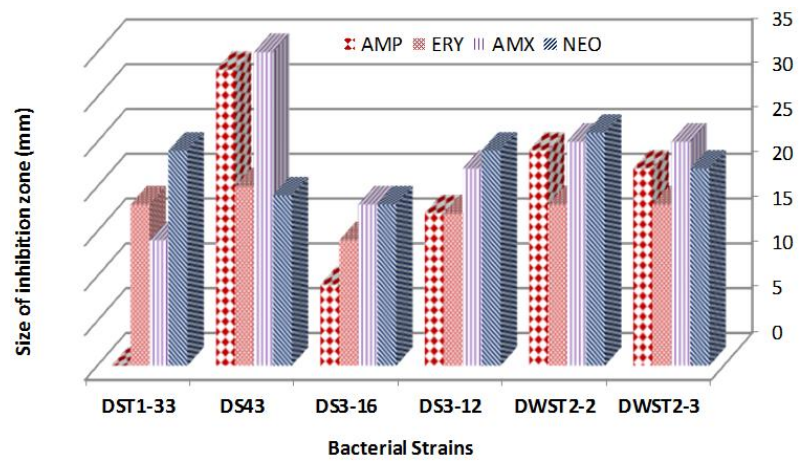

Fig. 2a: Antibiotic sensitivity profiling among the most resistant PHB-producing candidates

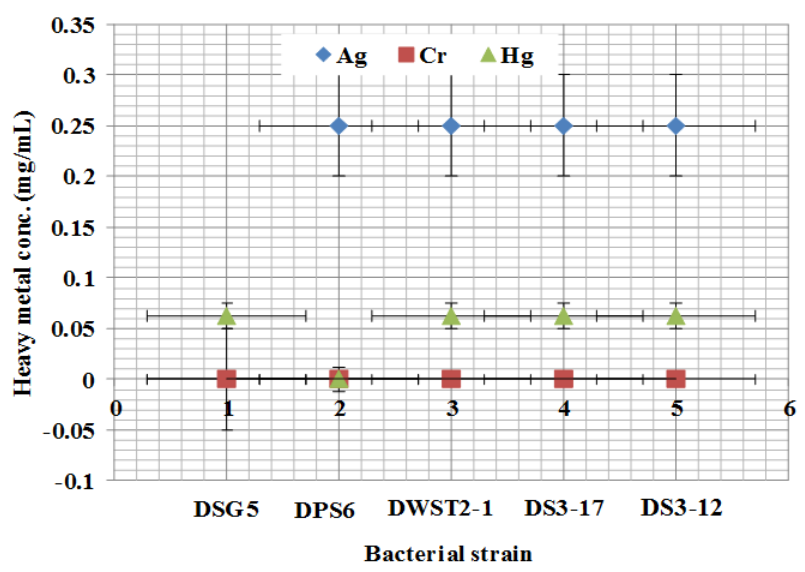

Fig. 2b: Heavy metal resistance among the most tolerant PHB-producing candidates

2006). In parallel, antibiotics misuse in different activities e.g. agriculture, hospitals, animal farming and industry, might pose serious pressure on microbes leading to mutations and other modifications. Therefore, it is recommended to explorer the PHB-producing strains regarding resistance to heavy metal and antibiotics for controlling contamination before industrial production of the biopolymer (De Lima et al., 1999; Rehman et al., 2007).

Except ampicillin, erythromycin, amoxicillin and neomycin, most of PHB-producing candidates showed higher susceptibility to antibiotics (Fig. 2) and heavy metals except $\mathrm{Ag}, \mathrm{Cr}$ and $\mathrm{Hg}$, respectively. Most of these bacterial candidates isolated from wild environment which might be the reason for limited number of resistance markers. In contrast, Naheed et al. (2011) showed that many of PHAs producing strains were resistant to multiple markers like commonly used antibiotics (penicillin and streptomycin) and heavy metals $(\mathrm{Cu}$ and $\mathrm{Cd})$. The $\mathrm{Cu}^{+2}$ ion resistance $(>6.5 \mathrm{mM})$ was more common among a population of PHBproducing bacteria (Chen et al., 2001). Interestingly, some heavy metals, like copper II, trigger the biosynthesis and accumulation of PHB in some bacteria e.g., Azospirillum brasilense strains Sp7 (Kamnev et al., 2012). Furthermore, in Cupriavidus taiwanensis EJ02, phylogenetically related to Ralstonia eutropha, the presence of heavy metals especially cadmium ions might be associated with its ability to accumulate PHB and to adapt to environmental stress (Chien et al., 2014).

On the other hand, toxicity of producing organism might have negative impact on the process regarding biotechnological production of the biopolymer in large scale. In this study, four isolates including; $B$. cereus strain DS3-16 and strain DS3-12, B. thuringiensis strain DST1-33 and $B$. pseudomycoides strain DWST2-1 showed $\beta$ hemolysis activity, while $B$. axarquiensis strain DSG5 showed $\alpha$-hemolytic activity, reflecting their possible toxicity. In fact, B. cereus group includes well known candidates showed powerful hemolytic activity and capable of causing food poisoning with diarrhea (Phelps and McKillip, 2002; Hendriksen et al., 2006; Didelot et al., 2009). On the other hand, B. mycoides strain DWST2-2, $B$. aryabhattai strain DBS10, B. endophyticus DS43 and $B$. megaterium strain DP7 are common soil non-pathogenic bacteria, recorded no hemolytic activity, thus can be advantageous in terms of PHB production. Indeed, immunological characteristics of these bacteria should be intensively investigated to ensure the safety of these bacterial candidates during biotechnological production of PHB in large scale.

\section{Conclusion}

Bacillus mycoides DWST2-2, B. aryabhattai DBS10, B. endophyticus DS43 and B. megaterium DP7 are common soil non-pathogenic bacteria, recording no hemolytic activity, thus can be used for biotechnological production of the PHB biopolymer.

\section{Acknowledgements}

This work was funded by Deanship of Scientific Research, University of Dammam, Saudi Arabia (Grant Application No. 2014045). 


\section{References}

Aarthi, N. and K.V. Ramana, 2011. Identification and Characterization of Polyhydroxybutyrate producing Bacillus cereus and Bacillus mycoides strains. Int. J. Environ. Sci., 5: 744-756

Baquero, F., M.C. Negri, M.I. Morosini and J. Blazquez, 1998. Antibioticselective environments. Clin. Inf. Dis., 27: S5-S11

Bauer, A.W., W.M.M. Kirby, J.C. Sherris and M. Turck, 1966. Antibiotic susceptibility testing by a standardized single disc method. Amer. J. Clin. Pathol., 45: 493-496

Berekaa, M.M. and A.M. Al-Thawadi, 2012. Biosynthesis of Polyhydroxybutyrate (PHB) biopolymer by Bacillus megaterium SW1-2: application of Box-Behnken design for optimization of process parameters. Afr. J. Microbiol. Res., 6: 838-845

Borah, B., P.S. Thakur and J.N. Nigam, 2002. The influence of nutritional and environmental conditions on the accumulation of polybhydroxybutyrate in Bacillus mycoides RLJ B-017. J. Appl. Microbiol., 92: 776-783

Chen, G.Q., 2010. Plastics from Bacteria: Natural Functions and Applications. Microbiology Monographs: Springer-Verlag Berlin Heidelberg, Germany

Chen, G.Q., K.H. Konig and R.M. Lafferty, 1991. Occurrence of poly-D (-)3-hydroxyalkanoates in the genus Bacillus. FEMS Microbiol. Lett., 84: $173-176$

Chen, G.Q. and Q. Wu, 2005. The application of polyhydroxyalkanoates as tissue engineering materials. Biomaterials, 26: 6565-6578

Chen, G., Q. Wu and J. Chen, 2001. Biosynthesis of Polyhydroxyalkanoates. Tsinghua Sci. Technol., 6: 193-199

Chien, C.C., L.J. Wang and W.R. Lin, 2014. Polyhydroxybutyrate accumulation by a cadmium-resistant strain of Cupriavidus taiwanensis. J. Taiw. Inst. Chem. Eng., 45: 1164-1169

De Lima, T.C.S., B.M. Grisi and M.C.M. Bonato, 1999. Bacteria isolated from a sugarcane agroecosystem: their potential production of polyhydroxyalcanoates and resistance to antibiotics. Rev. Microbiol., 30: 214-224

Didelot, X., M. Barker, D. Falush and F.G. Priest, 2009. Evolution of pathogenicity in the Bacillus cereus group. Syst. Appl. Microbiol., 32: $81-90$

El-Helow, E.R., 2001. Identification and molecular characterization of a novel Bacillus strain capable of degrading Tween-80. FEMS Microbiol Let., 196: 119-122

Hendriksen, N.B., B.M. Hansen and J.E. Johansen, 2006. Occurrence and pathogenic potential of Bacillus cereus group bacteria in a sandy loam. Ant van Leeuwenhoek, 89: 239-249

Hoseinabadi, A., I. Rasooli and M. Taran, 2015. Isolation and identification of poly $\beta$-hydroxybutyrate over-producing bacteria and optimization of production medium. Jundishapur J. Microbiol.,8: 6965

Kamnev, A.A., A.V. Tugarova, P.A. Tarantilis, P.H.E. Gardiner and M.G. Polissiou, 2012. Comparing poly-3-hydroxybutyrate accumulation in Azospirillum brasilense strains $\mathrm{Sp} 7$ and Sp245: The effects of copper (II). Appl. Soil Ecol., 61: 213-216

Kim, Y.B. and R.W. Lenz, 2001. Polyesters from microorganisms. Adv. Biochem. Eng. Biotechnol., 71: 51-79

Krishnani, K.K. and S. Ayyappan, 2006. Heavy Metals Remediation of Water Using Plants and Lignocellulosic Agrowastes. Rev. Environ. Contam. Toxicol., 188: 59-84

Lee, S.Y., J.I. Choi, K. Han and J.Y. Song, 1999. Removal of Endotoxin during Purification of Poly (3-Hydroxybutyrate) from GramNegative Bacteria. Appl. Environ. Microbiol., 65: 2762-2764

Logan, N.A., L. Lebbe, B. Hoste, J. Goris, G. Forsyth, M. Heyndrickx, B.L. Murray, N. Syme, D.D. Wynn-Williams and P. De Vos, 2000 Aerobic endospore-forming bacteria from geothermal environments in northern Victoria Land, Antarctica, and Candlemas Island, South Sandwich archipelago, with the proposal of Bacillus fumariolisp. nov. Int J Sys Evol Microbiol., 50: 1741-1753

Lopez-Cortes, A., O. Rodriguez-Fernandez, H. Latisnere-Barragan, H.C. Mejia-Ruı, G. Gonzalez-Gutierrez and C. Lomelı-Ortega, 2010. Characterization of polyhydroxyalkanoate and the phaC gene of Paracoccus seriniphilus E71 strain isolated from a polluted marine microbial mat. World J. Microbiol. Biotechnol., 26: 109-118
Luengo, J.M., B. Garcia, A. Sandoval, G. Naharro and R.E. Olivera, 2003. Bioplastics from microorganisms. Curr. Opin. Microbiol., 6: 251260

Madison, L.L. and G.W. Huisman, 1999. Metabolic engineering of poly(3hydroxyalcanoates): From DNA to plastic. Microbiol. Mole. Biol. Rev., 63: 21-53

Mizuno, K., A. Ohta, M. Hyakutake, Y. Ichinomiya and T. Tsuge, 2010. Isolation of polyhydroxyalkanoates-producing bacteria from a polluted soil and characterization of the isolated strain Bacillus cereus YB-4. Polym Degrad Stab., 95: 1335-1339

Mokhtari-Hosseini, Z.A., E. Vasheghani-Farahani, A. HeidarzadehVazifekhoran, S.A. Shojaosadati, R. Karimzadeh and K.K. Darani, 2009. Statistical media optimization for growth and PHB production from methanol by a methylotrophic bacterium. Biores. Technol., 100: 2436-2443

Naheed, N., N. Jamil and S. Hasnain, 2011. Screening of contaminated soils for biodegradable plastic producing bacteria and profiling of their resistance markers. Afr. J. Microbiol. Res., 5: 4097-4104

Narayanan, A. and K.V. Ramana, 2012. Polyhydroxybutyrate production in Bacillus mycoides DFC1 using response surface optimization for physico-chemical process parameters. Biotechnology, 2: 287-296

Nayak, P.K., A.K. Mohanty, T. Gaonkar, A. Kumar, S.N. Bhosle and S. Garg, 2013. Rapid Identification of Polyhydroxyalkanoate Accumulating Members of Bacillales Using Internal Primers for phaC Gene of Bacillus megaterium. ISRN Bacteriol., Article ID 562014,12 pages

Ojumu, T.V., J. Yu and B.O. Solomon, 2004. Production of Polyhydroxyalkanoates, a bacterial biodegradable polymer. Afr. J. Biotechnol., 3: 18-24

Phelps, R.J. and J.L. McKillip, 2002. Enterotoxin Production in Natural Isolates of Bacillaceae outside the Bacillus cereus Group. Appl. Environ. Microbiol., 68: 3147-3151

Razzaq, A., N. Jamil, N. Naheed and S. Hasnain, 2010. Bacteria from contaminated urban and hilly areas as a source of polyhydroxyalkanoates production. Afr. J. Biotechnol., 9: 1919-1925

Reddy, S.V., M. Thirumala and S.K. Mahmood, 2009. Production of PHB and $\mathrm{P}(3 \mathrm{HB}-\mathrm{co}-3 \mathrm{HV})$ biopolymers of Bacillus megaterium strain OU303A isolated from municipal sewage sludge. World $J$. Microbiol. Biotechnol., 25: 391-397

Rehman, S.U., N. Jamil and S. Husnain, 2007. Screening of different contaminated environments for polyhydroxyalkanoates-producing bacterial strains. Biologia, 62: 650-656

Singh, M., S.K.S. Patel and V.C. Kalia, 2009. Bacillus subtilis as potential producer for polyhydroxyalkanoates. Microb. Cell Fact., 8: 1-11

Steinbuchel, A., 2001. Perspectives for Biotechnological Production and Utilization of Biopolymers: Metabolic Engineering of Polyhydroxyalkanoate Biosynthesis Pathways as a Successful Example. Macromol. Biosci., 1: 1-24

Valappil, S.P., S.K. Misra, A.R. Boccaccini, T. Keshavarz, C. Bucke and I. Roy, 2007. Large-scale production and efficient recovery of PHB with desirable material properties, from the newly characterized Bacillus cereus SPV. J. Biotechnol., 132: 251-258

van der Walle, G.A., G.J. de Koning, R.A. Weusthuis and G. Eggink, 2001. Properties, modification, and application of biopolyesters. Adv. Biochem. Eng. Biotechnol., 71: 263-291

Wu, Q., H. Huang, G. Hu, J. Chen, K.P. Ho and G.Q. Chen, 2001. Production of poly-3-hydroxybutyrate by Bacillus sp. JMA5 cultivated in molasses media. Ant. van Leeuwenhoek, 80: 111-118

Yilmaz, M., H. Soran and Y. Beyatli, 2005. Determination of polybhydroxybutyrate (PHB) production by some Bacillus sp. World J. Microbiol. Biotechnol., 21:565-566

Zinn, M., B. Witholt and T. Egli, 2001. Occurrence, synthesis and medical application of bacterial polyhydroxyalkanoate. Adv. Drug Deliv. Rev., 53: 5-21

(Received 12 August 2016; Accepted 22 September 2016) 